\title{
Multi-dimensional factors associated with unprotected anal intercourse with regular partners among Chinese men who have sex with men in Hong Kong: a respondent-driven sampling survey
}

Yong Cai ${ }^{1}$ and Joseph T F Lau ${ }^{2 *}$

\begin{abstract}
Background: The HIV prevalence and incidence among men who have sex with men (MSM) are high. Unprotected anal intercourse (UAI) with male regular partners (RP) is an important but under-emphasized risk behavior. The current study aimed to describe the prevalence of UAI with regular partner and the associated multi-dimensional factors with UAl among MSM in Hong Kong, China.

Methods: Respondent Driven Sampling method was used to recruit participants. A total of 285 participants were recruited, of whom 211 (75.1\%) had had anal sex with RP in the last six months and their data were analyzed in this report. Weighed data were presented and logistic regression methods were fit.

Results: Participants' high risk behaviors in the last six months included high prevalence of having had UAI with RP (45.8\%), having had non-regular male sex partners (NRP: 27.3\%) and UAI with such partners (18.9\%). Adjusted for socio-demographic variables, factors associated with UAI with RP included: 1) substances use prior to having anal sex (65.7\% versus 43.8\%; $\mathrm{AOR}=2.36 ; 95 \% \mathrm{Cl}=1.07-5.18)$, 2) worry that condom use symbolizes mistrust (67.9\% versus $44.3 \% ; \mathrm{AOR}=2.91 ; 95 \% \mathrm{Cl}=1.19-7.10), 3)$ a lower perceived degree of the RP's acceptance of condom use (91.7\% versus 38.3\%; $A O R=22.70 ; 95 \% \mathrm{Cl}=6.20-83.10)$, and 4 ) a higher level of impulsivity (61.1\% versus 35.0\%; $A O R=4.02$; $95 \% \mathrm{Cl}=1.62-9.97)$. Two of these four variables, substances use $(\mathrm{ORm}=2.28,95 \% \mathrm{Cl}=1.01-5.16)$ and perceived lower level of RP's acceptance of condom use (ORm $=17.22 ; 95 \% \mathrm{Cl}=5.06-58.62)$ were selected by the forward stepwise logistic regression model.
\end{abstract}

Conclusions: MSM with RP in Hong Kong is subjected to high risk of HIV transmission. Risk factors of UAl are multi-dimensional and interventions need to take into account factors of structural, interpersonal and individual levels. Keywords: Men who have sex with men, Respondent driven sampling, Regular partner, Unprotected anal intercourse

\footnotetext{
* Correspondence: jlau@cuhk.edu.hk

${ }^{2}$ Centre for Health Behaviors Research, School of Public Health and Primary Care, Faculty of Medicine, The Chinese University of Hong Kong, 5/F., School of Public Health, Prince of Wales Hospital, Shatin, NT, Hong Kong 030000, PR China

Full list of author information is available at the end of the article
} 


\section{Background}

The human immunodeficiency virus (HIV) epidemic among men who have sex with men (MSM) in China is a public health threat as the HIV prevalence in this population has been high and keeps increasing [1-3]. According to a national survey in 2011, the average HIV prevalence among MSM in China was 4.9\% [4]. In Hong Kong, the HIV prevalence among MSM was $4.08 \%$ in 2011 [5]. According to social marketing principles, the target population should not be seen as a homogeneous group and segmentation is required to improve effectiveness of interventions [6]. In this context, previous research has shown that the prevalence of unprotected anal intercourse (UAI) with male regular sex partners (RP) is significantly higher than that with male nonregular sex partners (NRP) among MSM [7]. UAI with RP among MSM contributes to the majority of the new HIV infections in the United States and in Lebanon $[8,9]$. Among the $61.4 \%$ of the MSM in China having RP, $78.6 \%$ also have had sexual intercourse with other male sex partners $[10,11]$. The proportion of new HIV infections attributable to sexual intercourse with RP, NRP and commercial sex partners (CSP) among MSM was $40 \%, 37 \%$ and $23 \%$ respectively in 2010 in China [10]. The proportion of new infections attributable to RP among MSM was 34\% in 2002, and with an increase of $6 \%$, infections attributable to RP among MSM started to prevail in the past decade in China [10]. It seems that HIV prevention in China are mainly venue-based (gaysaunas and bars) and hence focuses mainly on promoting safer sex with NRP [10]. Furthermore, a cohort study targeting MSM has shown that UAI with RP but not UAI with NRP predicts HIV sero-conversion [12]. Hence, the risk of HIV transmission via male RP among MSM is important but may have been overlooked.

Furthermore, our literature search did not locate any study reporting HIV intervention specifically promoting condom use with RP among MSM. To design such programs effectively, we need to identify multi-dimensional risk factors associated with UAI with male RP among MSM. Previous studies have shown that intimacy between heterosexual sex partners is associated with inconsistent condom use $[13,14]$. It is also seen that worry about breaching the trust is one of the obstacles hindering condom use between heterosexual regular partners [15]. A few studies have tested similar hypotheses among MSM indicating that trust, emotional connection with the partner, and intimacy were significant predictors of UAI [16-18]. Cognitive factors are known to be significantly associated with UAI among MSM [19] and HIV/ sexual transmitted infection (STI) risk perception is one of such factors [18-20]. Very few, if any, studies investigated specific assessment of the risk level of one's RP among MSM [21]. This is important as monogamy does not seem to be the norm among MSM [22,23]. Assessment of the perceived risk of contracting HIV via the RP is equally important, as that may cause severe damage to the relationship with the RP, sense of anger, guilt and regret [24]. Previous studies targeting MSM that did not focus specifically on UAI with RP have reported significant contextual factors $[19,25]$, one of which was the use of alcohol and substances prior to having anal sex with men [26-28]. Relatively few studies studied the importance of this factor with respect to UAI with RP among MSM $[27,28]$.

Personality of the MSM is another important but often under-investigated risk factor [29]. Impulsivity usually displays behaviors characterized by little or no forethought, reflection, or consideration of the consequences; it has found to be significantly associated with various types of risk factors such as alcohol abuse [30]. Impulsivity is also likely to be related to HIV risk-particularly in incarcerated substance-abusing youth [31]. A study revealed that the relationship between intensity of methamphetamine use and total unprotected sex was strongest among participants who had higher levels of impulsivity among HIVpositive MSM [32]. According to our knowledge, no study has investigated the association between impulsivity and UAI with RP among MSM.

Respondent driven sampling (RDS) is a relatively new research method designed for collecting data from hardto-reach populations [33]. It has been used in studies targeting MSM in China [34] and in other countries $[35,36]$. It requests participants to refer a fixed number of eligible prospective participants (usually three to five) to join a survey, while similar waves are repeatedly conducted until the required sample size is achieved. Incentives are usually involved when referrals are being made. Theoretically, an equilibrium state would be attained after several waves of recruitment, and unbiased statistical estimates approaching those obtained from random probability sampling would be obtained $[33,35]$. The RDS design is hence an improvement over the venuebased sampling method commonly used in HIV research targeting MSM [36,37].

This study investigated prevalence of UAI specifically with RP among Chinese MSM in Hong Kong, China. Multi-dimensional factors were investigated at different levels, including i) the individual's background factors (socio-demographic variables such as age, educational level, marital status, and sexual orientation, etc.); ii) contextual factors (use of alcohol and substances prior to having anal intercourse); iii) interpersonal factors (intimacy with the RP, worry that condom use symbolizes mistrust, perceived degree of the RP's acceptance of condom use, perceived HIV/STI risk level of the RP; and iv) personality factor (impulsivity). It is hypothesized that the aforementioned factors would be associated independently with UAI with RP among MSM. 


\section{Methods}

\section{Study population and sampling}

The fieldwork was conducted during March 2009 through October 2009. Inclusion criteria were: age of at least 18 years old, residents of Hong Kong, and self-reporting having had anal sex with at least one man in the last 6 months. Prospective participants were informed that the survey was anonymous and would take 20 to 30 minutes to complete and its purpose is to improve health of the MSM in Hong Kong. Using RDS procedures, seven initial eligible participants served as seeds. In the first wave, the seven seeds each recruited a maximum of three participants whom similarly recruited a second wave of three or less participants. Each new potential participant obtained three coupons containing information about the study and the eligibility criteria for referrals. The RDS method usually can achieve equilibrium after five to six waves of referrals $[38,39]$. In this study, a total of 285 eligible MSM were recruited by the seven seeds. The sample size was hence 294. Equilibrium was reached at Wave 5, regarding distributions on socio-demographics (age, educational level, marital status, and employment status), sexual orientation, and history of HIV voluntary counseling \& testing (VCT). The average network size was 21. Each participant received a monetary compensation of HK\$ 100 (about USD 12) for the time spent.

Of all these participants, 211 (75.1\%) of the participants had had anal sex with the RP, 131 (46.6\%) had had anal sex with NRP; seven (2.5\%) had had sex with CSP in the last six months. Those with RP were asked all the questions presented in this report, while those without RP ( $n=74)$ were excluded from the analysis as they were asked a different set of questions (e.g. those related to different types of venue used to recruit those NRP and their social network) instead of questions included in this report, data of which were not described in this report. The purpose of this paper was hence to look specifically at UAI with RP and involved a sample of 211 MSM who had had anal sex with RP in the last six months. For those with more than one RP in the last six months, they were asked to make reference to the RP who had had the most recent episode of anal sex when answering the questions.

\section{Ethical considerations}

Anonymous interviews were administered. The survey presented no more than minimal risk or harm to the participants. Participants were briefed in detail about the study. Verbal informed consent was then obtained before commencement of the interview. Written informed consent was not obtained to maintain absolute anonymity. Interviewers were however requested to sign a form pledging that they had made clear explanations to the participants and answered all questions before the participants signed the informed consent. Such a consent procedure has been used in similar studies $[40,41]$. The ethics committee of Chinese University of Hong Kong approved the recruitment procedure and the protocol described in this study.

\section{Measures \\ Background characteristics}

Information on background characteristics was collected, including socio-demographic variables (age, educational level, marital status, and employment status), sexual orientation, history of HIV voluntary counseling \& testing (VCT). Participants were asked whether they had had anal sex with two other different types of male sex partners (NRP, and CSP) in the last six months and whether they had had UAI with the RP and the two other types of male sex partners.

\section{Contextual variables}

Contextual variables included the use of alcohol and substances prior to having anal intercourse with the RP in the last six months.

\section{Interpersonal-level variables}

Four interpersonal-level variables were included in this study. First, intimacy with RP was assessed by four items ('You are satisfy with the relationship with your RP', 'You have a close relationship with your RP', 'You are equal in the relationship with your RP' and 'You can depend on your RP to solve private problem'), each with three response categories (1-no, 2-not sure, 3-yes). A summative composite scale was formed with a factor analysis identifying one single factor ( $\%$ variance explained $=54.63 \%$; Cronbach's alpha coefficient $=0.631$, mean $=10.9 \pm 1.8$, range $=4-12)$. Higher scores indicated a closer relationship with the regular partner(s). Second, we assessed the degree of worry that condom use symbolizes mistrust by using a single item ("Do you worry that condom use during anal sex symbolizes mistrust between you and your RP"); the response was recode into a binary measure (yes and no/not sure). Third, perceived degree of the RP's acceptance of condom use was assessed by using three questions ('You can persuade your RP to use condom if you want to', 'Your $R P$ supports the use of condom' and 'you and your RP have reached a consensus over condom use'). The response categories were 'yes', 'not sure' and 'no'. A composite scale was constructed by counting the number of item response reflecting perceived RP's acceptance on condom use. Fourth, perceived HIV/STI risk level of the RP was gauged by asking three questions ('Your RP has ever been infected with STI', 'Your RP has high risk behaviors for contracting HIV'; 'You have much chance of contracting HIV via your $R P^{\prime}$ ); these questions had three response categories ('yes', 'not sure' and 'no'). A composite indicator variable was 
created by counting the number of item response reflecting perceived HIV/STI risk level of the RP.

\section{Personality variable}

The Chinese version of the 19-item Impulsiveness Scale of the I7 questionnaire was used as the measure of impulsivity [42]. Impulsivity is regarded as acting without first considering the possible consequences. I7 Impulsiveness Scale contains 19 items (e.g. 'Are you an impulsive person', and 'Do you usually think carefully before doing anything?'). Respondents answered the items by giving dichotomous ('yes' and 'no') responses. This scale assesses the personality trait of impulsivity with good reliability and validity [42,43]. The sum of 19 item scores was converted into a total score (Cronbach's alpha coefficient $=$ 0.71 ; mean $=5.3 \pm 2.1$; range $=0$-19). Higher scores mean higher impulsivity.

\section{Creation of categorical variables for the composite scores}

For the composite variables of intimacy with RP and impulsivity were recode into three groups according to the percentiles of the scores (low: <25th percentile, middle: $25-75$ percentiles, high: $>75$ th percentiles).

\section{Statistical analysis}

RDS data were analyzed by the respondent-driven sampling analysis tool (RDSAT). Weighed estimates based on RDS II estimators [44], taking into account the network size and recruitment pattern, were derived. Univariate odds ratios $(\mathrm{ORu})$ and their respective $95 \%$ confidence intervals (CI) were presented. Adjusted odds ratios (AOR) were estimated. In addition, multiple forward stepwise logistic regression models were fit, using all variables with $\mathrm{p}<0.05$ in the univariate analysis as candidates and adjusted for background variables. Statistical significance was defined by $\mathrm{p}$ value $<0.05$. Other statistical analyses were conducted by using SPSS 16.0 for windows.

\section{Results}

\section{Profile of participants}

Of the 211 participants, weighted estimates showed that $53.6 \%$ of them were of age 20 to 30 years old; $60.1 \%$ had attained college or university education; $97.7 \%$ were never married; $78.6 \%$ were full-time workers. Of them, $87.3 \%$ expressed that they were gay; only $33.5 \%$ of them had ever taken up VCT in the last six months (Table 1).

\section{Sexual risk behaviors in the last six months}

In the last six months, $27.3 \%$ had had anal sex with NRP and $2.4 \%$ of the sample had had anal sex with CSP during the same six-month period. The prevalence of UAI with male RP and NRP in the last six months was $45.8 \%$ and $18.9 \%$ respectively (Table 1 ).
Table 1 Crude and adjusted estimates of characteristics of MSM with RP in Hong Kong ( $N=211)$

\section{n (Crude \%) Weighted \%*} $(95 \% \mathrm{Cl})$

\section{Socio-demographics}

Age group (years)

$<20$

20-30

25 (11.8)

$14.1(9.5-18.8)$

$31-40$

$121(57.3)$

$53.6(46.5-60.7)$

$>40$

$53(25.2)$

$25.9(21.1-30.8)$

Highest education level

Junior high school or less

$12(5.7)$

$6.4(2.8-9.3)$

Senior high school

$9(4.3)$

$6.7(3.8-9.6)$

College or university

$58(27.5)$

$33.2(30.1-36.3)$

Current marital status

Single

$144(68.2)$

$60.1(52.7-67.5)$

Married

206 (97.6)

$97.7(95.6-99.8)$

Full-time employment

No

$5(2.4)$

$2.3(0.2-4.4)$

54 (25.6)

$21.4(13.6-28.9)$

Yes

$157(74.4)$

$78.6(71.1-86.4)$

Self-reported sexual orientation

Gay/Homosexual

$183(86.7)$

$87.3(80.2-92.4)$

Bisexual

$28(13.3)$

$12.7(7.6-19.8)$

Ever tested for HIV in the last six months

No

$129(61.1)$

$66.5(59.2-72.0)$

Yes

$82(38.9)$

$33.5(28.0-40.8)$

\section{Sexual risk behaviors in the last six months}

Have had anal sex both with RP and NRP

No

Yes

Have had anal sex both with RP and CSP

No

$\begin{array}{ll}207(98.1) & 97.6(95.8-99.0) \\ 4(1.9) & 2.4(1.0-4.2)\end{array}$

Yes

$$
4(1.9)
$$

$2.4(1.0-4.2)$

\section{Have UAI with RP}

No

Yes

$\mathrm{Ha}$

$100(47.4)$

$45.8(37.7-56.4)$

No

44 (78.6)

$81.2(43.6-62.3)$

Yes

$12(21.4)$

$18.9(37.7-56.4)$

*Respondent driven sampling data were adjusted according to the network size and recruitment.

Patterns; $\mathrm{Cl}$, confidence interval.

\section{Item responses of the contextual, inter-personal and} personality variables

Respectively $14.7 \%$ and $10.4 \%$ had had used substances and alcohol prior to having anal sex with the RP. The 
Table 2 Crude and adjusted estimates of the frequency distributions of the contextual variables, interpersonal variables and personality variable among MSM with RP $(\mathrm{N}=\mathbf{2 1 1})$

\begin{tabular}{lll}
\hline n (Crude \%) & $\begin{array}{l}\text { Weighted \%* } \\
(95 \% \mathrm{Cl})\end{array}$ \\
\hline Contextual variables &
\end{tabular}

Substances use prior to having anal sex with the RP

No
Yes

Alcohol use prior to having anal sex with the RP

No

Yes

\section{Interpersonal variables}

Intimate relationship with $R P$

You are satisfy with the relationship with your RP regular partner

No

Not sure

Yes

You have a close relationship with your RP

No

Not sure

Yes

You are equal in the relationship with your RP

No

Not sure

Yes

You can depend on your RP to solve private problem

No

Not sure

Yes

Level of intimacy with $R P$

Low level $\left(<P_{25}\right.$ or $\left.<10\right)$

Middle level $\left(\mathrm{P}_{25-75}\right.$ or 10-11)

High level $\left(>P_{75}\right.$ or $\left.>11\right)$

Worry that condom use symbolizes mistrust

Yes

No

Perceived degree of the RP's acceptance of condom use

You can persuade your RP to use condom if you want to

No or Not sure

$\begin{array}{ll}176(83.4) & 85.3(81.5-89.2) \\ 35(16.6) & 14.7(10.8-18.5)\end{array}$

189 (89.6) $89.3(84.2-93.9)$

$22(10.4)$

$10.7(6.1-15.8)$

(10.7)

$23(10.9) \quad 11.5(9.9-12.8)$

$3(1.4) \quad 1.9(1.1-2.6)$

185 (87.7) $\quad 86.6(84.4-88.9)$

$31(14.7)$

$3(1.4)$

$177(83.9)$

$15.1(14.2-16.0)$

$1.9(1.2-2.7)$

$83.0(80.4-85.6)$

$11(5.2)$

$2(0.9)$

$198(93.8)$

$1.3(0.7-1.9)$

$91.9(88.5-95.2)$

$44(20.9)$

$2(0.9)$

$165(78.2)$

$21.7(9.2-19.0)$

$1.2(0.7-1.7)$

$77.1(73.8-80.5)$

28 (13.3)

$14.8(9.2-19.0)$

45 (21.3)

$138(65.4)$

$21.9(17.7-26.8)$

$63.3(58.4-67.5)$

28 (13.3)

14.9 (9.4-19.5)

$183(86.7)$

$85.1(80.5-91.6)$
$6.8(4.7-8.9)$

Table 2 Crude and adjusted estimates of the frequency distributions of the contextual variables, interpersonal variables and personality variable among MSM with RP ( $\mathbf{N}=\mathbf{2 1 1}$ ) (Continued)

\begin{tabular}{lll}
\hline Yes & $193(91.5)$ & $90.2(88.4-92.8)$
\end{tabular}

Your RP supports the use of condom

No or Not sure

$\begin{array}{ll}24(11.4) & 12.1(9.7-14.5) \\ 187(88.6) & 87.9(85.5-90.3)\end{array}$

Yes

$$
187(88.6)
$$

You and your RP have reached a

consensus over condom use

$\begin{array}{lll}\text { No or Not sure } & 10(4.8) & 5.9(4.1-7.7) \\ \text { Yes } & 201(95.3) & 94.1(92.3-95.9)\end{array}$

Number item responses reflecting

$P R$ 's acceptance of condom use

$\begin{array}{lll}<3 \text { (lower acceptance) } & 36(17.1) & 19.4(13.7-22.8) \\ =3 \text { (higher acceptance) } & 175(82.9) & 80.6(77.2-86.3)\end{array}$

Perceived HIVISTI risk level of the RP

Your RP has ever been infected with STI

Yes or Not sure

$45(21.3)$

$20.1(17.6-24.3)$

No

$166(78.7)$

$79.9(75.7-82.4)$

Your RP has high risk behaviors for contracting HIV

No

$52(24.6)$

$22.8(19.7-25.9)$

Yes or Not sure

$159(75.4)$

$77.2(74.1-80.3)$

You have much chance of contracting HIV via your RP

No

$46(21.8)$

$20.7(18.0-24.8)$

Yes or Not sure

$165(78.2)$

$79.3(75.2-82.0)$

Number item responses reflecting HIV/STI risk level of the RP

$>0$ (higher HIV/STI perceived risk level)

$67(31.8)$

$30.3(26.1-35.7)$

$=0$ (lower HIV/STI perceived risk level)

$144(68.2)$

$69.7(64.3-73.9)$

Personality variable

17 Impulsiveness Scale

Low level $\left(<P_{25}\right.$ or $\left.<4\right) \quad 40(19.0) \quad 20.3(16.4-25.1)$

Media level $\left(P_{25-75}\right.$ or 4-6) $\quad 117(55.5) \quad 56.7(51.9-60.6)$

High level $\left(>P_{75}\right.$ or $\left.>6\right) \quad 54(25.6) \quad 23.0(19.1-27.8)$

*Respondent driven sampling data were adjusted according to the network size and recruitment.

Patterns; $\mathrm{Cl}$, confidence interval.

majority (close to $80 \%$ or more) of the participants gave item responses reflecting intimate relationship with the RP (77.1 to 91.9\%) and perceived RP's acceptance over condom use (87.9 to $94.1 \%)$ and did not worry that condom use symbolizes mistrust (85.1\%; see Table 2 ). The majority (79.9\%) of the participants' RP had not contracted STI, while only about $20 \%$ of the participants clearly indicated that they did not perceived their RP as not having high risk behaviors for contracting HIV (77.2\%) and that 
they did not perceived high risk of contracting HIV via their RP (20.7\%; see Table 2).

Factors associated with UAI with RP in the last six months None of the background variables presented in Table 3 was significantly associated with UAI with RP in the last six months. Adjusted for the socio-demographic factors listed in Table 1, variables that were significantly associated with the UAI with RP included (Table 4): 1) substances use prior to having anal sex with the RP (65.7\% versus $43.8 \%$; $\mathrm{AOR}=2.36$; $95 \% \mathrm{CI}=1.07-5.18), 2$ ) worry that condom use symbolizes mistrust between the participant and the RP $(67.9 \%$ versus $44.3 \%$; $\mathrm{AOR}=2.91$; 95\% CI $=1.19-7.10), 3$ ) a lower perceived degree of the RP's acceptance on condom use during anal sex (91.7\% versus $38.3 \%$; $\mathrm{AOR}=22.70 ; 95 \% \mathrm{CI}=6.20-83.10)$, and 4$)$ a higher level of impulsivity $(61.1 \%$ versus $35.0 \%$; AOR = 4.02; $95 \% \mathrm{CI}=1.62-9.97$ ). Two of these four variables related to substances use $(\mathrm{ORm}=2.28,95 \% \mathrm{CI}=1.01-5.16)$ and perceived lower level of RP's acceptance on condom use during anal sex $(\mathrm{ORm}=17.22 ; 95 \% \mathrm{CI}=5.06-58.62)$ were selected by fitting a forward stepwise logistic regression model (see Table 4). A number of variables were

Table 3 Associations between socio-demographic factors and UAI with RP among MSM $(n=211)$

\begin{tabular}{|c|c|c|}
\hline \multirow[b]{2}{*}{ Socio-demographics } & \multicolumn{2}{|c|}{ UAI with RP in the last six months } \\
\hline & n (row\%) & ORu $(95 \% \mathrm{Cl})$ \\
\hline \multicolumn{3}{|l|}{ Age group (years) } \\
\hline$<20$ & $9(36.0)$ & 1.00 \\
\hline $20-30$ & $57(47.1)$ & $1.58(0.65-3.86)$ \\
\hline $31-40$ & $29(54.7)$ & $2.15(0.81-5.72)$ \\
\hline$>40$ & $5(41.7)$ & $1.27(0.31-5.19)$ \\
\hline \multicolumn{3}{|l|}{ Highest education level } \\
\hline Junior high school or less & $3(33.3)$ & 1 \\
\hline Senior high school & $25(43.1)$ & $1.52(0.35-6.66)$ \\
\hline College or university & $72(50.0)$ & $2.00(0.48-8.31)$ \\
\hline \multicolumn{3}{|l|}{ Current marital status } \\
\hline Single & $98(47.6)$ & 1 \\
\hline Married & $2(40.0)$ & $0.74(0.12-4.49)$ \\
\hline \multicolumn{3}{|l|}{ Full-time employment } \\
\hline No & $25(46.3)$ & 1 \\
\hline Yes & $75(47.8)$ & $1.06(0.57-1.97)$ \\
\hline \multicolumn{3}{|l|}{ Self-report sexual orientation } \\
\hline Gay/Homosexual & $85(46.4)$ & 1 \\
\hline Bisexual & $15(53.6)$ & $1.33(0.60-2.95)$ \\
\hline \multicolumn{3}{|l|}{ Ever tested for HIV } \\
\hline No & 65 (50.4) & 1 \\
\hline Yes & $35(42.7)$ & $0.55(0.05-6.17)$ \\
\hline
\end{tabular}

ORu: univariate odds ratio; $95 \% \mathrm{Cl}$ : $95 \%$ confidence interval. found to be non-significant, including alcohol use prior to having anal sex with RP, intimacy with the RP and perceived HIV/STI risk level of the RP.

\section{Discussion}

The sampled MSM with RP were at high risk of HIV/ STD transmission. A previous study showed that UAI with RP but not that with NRP predicted HIV seroconversion [12]. In this study, prevalence of UAI with RP was high (45.8\%) and was comparable to that reported in a study conducted in Beijing in 2011 (49.7\%) [45], while it was lower than that obtained from studies conducted in Argentina (58.0\%) and Kazakhstan (69.0\%) $[35,46]$. Interventions focusing on UAI with RP among MSM are hence greatly warranted. Attention should also be given to sex with NRP among those with RP, as about $30 \%$ of the participants had had sex with NRP in the last six months and UAI was only involved. To socio-ecological model reminds us that we need to look at factors associated with UAI with RP among MSM at inter-personal, individual and structural levels [47].

Interpersonal factors need to be considered. Unlike results obtained from studies targeting heterosexual couples $[13,14]$, quality of relationship was not associated with UAI with RP in this study. The majority of the participants reported a good relationship with their RP. Other factors on relationship between the MSM and his RP (e.g. trust) were however, important. Many participants worried that condom use with the RP would be interpreted as mistrust. In this study and previous studies conducted in homosexuals and heterosexual populations $[13,14,16-18]$, the concern over mistrust was significantly associated with condom use during sexual intercourse. The data suggested that mistrust was common as one third of the participants believed that their RP was at high risk of HIV infection in the future or would pass HIV infection to them. The beliefs may be a reflection of the high prevalence of participants having both RP and NRP. In the context of mistrust but a good relationship, discussion about condom use might be avoided by the couple to minimize tension. A vicious cycle of perceived high risk of HIV transmission, mistrust, avoidance, and then perceived high risk might be created, which needs to be broken with improvement in communication skills through interventions. Furthermore, the absence of legal marriage to the same sex might further hinder MSM to form their families and remain monogamous. Structural factors therefore also need to be considered to improve the situation. Couplebased HIV interventions are warranted and have shown to be effective [48-50]. Difficulties include worry about separation, sexual abuse and sorry that such information would be a shock to the partner or would harm the partner [51].

Contextual individual-level factors such as psychoactive substance use prior to anal intercourse should be 
Table 4 Contextual, interpersonal and personality factors associated with UAI with RP in the last six months among $\operatorname{MSM}(\mathbf{n}=\mathbf{2 1 1})$

\begin{tabular}{|c|c|c|c|c|}
\hline & \multirow[b]{2}{*}{ n (row\%) } & \multicolumn{3}{|c|}{ UAl with RP in the last six months } \\
\hline & & ORu $(95 \% \mathrm{Cl})$ & AOR $(95 \% \mathrm{Cl})$ & ORm $(95 \% \mathrm{Cl})$ \\
\hline \multicolumn{5}{|l|}{ Contextual level } \\
\hline \multicolumn{5}{|l|}{ Substances use prior to having anal sex } \\
\hline No & $77(43.8)$ & 1.00 & 1.00 & \\
\hline Yes & $23(65.7)$ & $2.46(1.15-5.26)^{*}$ & $2.36(1.07-5.18)^{*}$ & $2.28(1.01-5.16)^{*}$ \\
\hline \multicolumn{5}{|l|}{ Alcohol use prior to having anal sex } \\
\hline No & $92(48.7)$ & 1 & 1 & NS \\
\hline Yes & $8(36.4)$ & $0.60(0.24-1.50)$ & $0.51(0.20-1.32)$ & \\
\hline \multicolumn{5}{|l|}{ Interpersonal level } \\
\hline \multicolumn{5}{|l|}{ Level of intimacy with the $R P$} \\
\hline Lower level $\left(<\mathrm{P}_{25}\right.$ or $\left.<10\right)$ & $13(46.4)$ & 1 & 1 & NS \\
\hline Middle level $\left(P_{25-75}\right.$ or 10-11) & $20(44.4)$ & $0.92(0.36-2.38)$ & $0.79(0.30-2.12)$ & \\
\hline Higher level $\left(>P_{75}\right.$ or $\left.>11\right)$ & $67(48.6)$ & $1.09(0.48-2.46)$ & $0.89(0.38-2.11)$ & \\
\hline \multicolumn{5}{|l|}{ Worry that condom use symbolizes mistrust } \\
\hline No & $81(44.3)$ & 1 & 1 & NS \\
\hline Yes or not sure & $19(67.9)$ & $2.66(1.14-6.19)^{*}$ & $2.91(1.19-7.10)^{*}$ & \\
\hline \multicolumn{5}{|l|}{ Number item responses reflecting HIV/STI risk level of the RP } \\
\hline$=0$ (lower perceived risk level of the RP) & $65(45.1)$ & 1 & 1 & NS \\
\hline$>0$ (higher perceived risk level of the RP) & $35(52.2)$ & $1.33(0.74-2.38)$ & $1.40(0.76-2.57)$ & \\
\hline \multicolumn{5}{|l|}{ Number item responses reflecting PR's acceptance of condom use } \\
\hline$=3$ (higher perceived degree of the RP's acceptance of condom use) & $33(38.3)$ & 1 & 1 & \\
\hline$<3$ (lower perceived degree of the RP's acceptance of condom use) & $67(91.7)$ & $17.7(5.23-60.09)^{* *}$ & $22.70(6.20-83.10)^{* *}$ & $17.22(5.06-58.62)^{* *}$ \\
\hline \multicolumn{5}{|l|}{ Personality level } \\
\hline \multicolumn{5}{|l|}{17 Impulsiveness Scale } \\
\hline Lower level $\left(<\mathrm{P}_{25}\right.$ or $\left.<4\right)$ & $14(35.0)$ & 1 & 1 & NS \\
\hline Middle level $\left(\mathrm{P}_{25-75}\right.$ or 4-6) & $53(45.3)$ & $1.54(0.73-3.24)$ & $1.84(0.85-4.01)$ & \\
\hline Higher level $\left(>P_{75}\right.$ or $\left.>6\right)$ & $33(61.1)$ & $2.92(1.25-6.82)^{*}$ & $4.02(1.62-9.97)^{* *}$ & \\
\hline
\end{tabular}

considered. In this study, the prevalence was about $15 \%$. Similar to the results of other studies [25,28], the variable was significantly associated with UAI. In China, there is no substance use prevention program targeting MSM. Such programs are different from those targeting the general population as sexual orientation and risks need to be considered. Prevention and risk reduction programs are warranted to fill up the service gap. In this study, alcohol use was not significantly associated with UAI among MSM. The result was similar to that of a recent conducted among Hong Kong MSM [7]. However, mixed findings of the associations between alcohol/drug use and UAI among MSM [7,46,51] have been reported.

Impulsivity is another important individual-level factor. Impulsivity is defined as acting without first considering the possible consequences is another important individual-level factor [32]. In this study and others, impulsivity refers to relatively stable personality and its measure was not specific to sex-related behaviors. It is potentially related to sexual adventurism, which is usually defined as sexual risk taking and sexual sensational seeking [52-54]. UAI is therefore related to sexual adventurism and sensational seeking $[52,54]$. Although previous studies have reported a significant association between higher impulsivity and unprotected sex among adult young women, high school students [51,55], drug users [56] and substanceabusing youth [31], this is the first study finding out that impulsivity was significantly associated with UAI during sex with RP among MSM. A study has shown greater intensity of methamphetamine use and higher levels of impulsivity predicted more unprotected sex among HIV-positive MSM, which suggests that targeting impulsivity in interventions may help reduce sexual risk behaviors [32]. Some interventions have been successful 
to instill stronger self-control on alcohol abuse and drug addiction $[57,58]$ and such components may need to be added to HIV interventions targeting this population of MSM.

The study has several limitations. The sample size was modest; some non-significant associations may be subjected to inadequate power. We used community based RDS method to increase representativeness. However, we were still unable to control for non-response bias. Non-random recruitment of peers by RDS method could influence the estimates in unknown ways [33]. The development of statistical analysis methods for RDS data was not readily available and risk factors analysis in the study was unweighted because the RDSAT does not entertain multivariate analyses. Data were selfreported and may involve reporting bias due to social desirability, while the survey was anonymous. Furthermore, the study did not involve HIV antibody testing and it is a limitation that we did not ask about HIV sero-status of the participants and their male regular sex partners. One of the reasons was that such data might not be reliable due to strong social desirability and may hence strongly be subjected to reporting bias. The HIV prevalence was about $4 \%$ in the study population, HIV testing rate (last six months) was rather low (about 33.5\%) and we do not have data about disclosure of HIV status to male regular sex partners. We do not know about the prevalence of sero-discordant couples among our participants but we contend that the number of such cases would be small. Some of the scales were constructed for this study and had not been validated as there are few studies specifically focused on UAI with RP among MSM.

\section{Conclusions}

In sum, the participants were at high risk of HIV/STI transmission as they have relatively high prevalence of having NRP and low prevalence of condom use with both RP and NRP. Participants in general, perceived that their RP might be at high risk of HIV/STI transmission. Issues arising from the relationship between such MSM and their RP, including feeling of mistrust associated with condom use, need to be addressed. Unlike the case of heterosexual risk factors, intimacy between the couple was however, not a significant factor. The issue on impulsivity has seldom been discussed in HIV prevention targeting MSM. It was a significant factor and further studies on interventions to increase self-control are warranted. Overall, HIV interventions aiming at reduction of UAI with RP among MSM need to consider multi-dimensional and socio-ecological factors at structural, interpersonal and individual levels. Lastly, the study used RDS method for data collection and hence to reduce sampling bias.

\section{Abbreviations}

RDS: Respondent driven sampling; MSM: Men who have sex with men; HIV: Human immunodeficiency virus; UAI: Unprotected anal intercourse; RP: Regular partners; NRP: Non-regular male sex partners; CSP: Commercial sex partners; STI: Sexual transmitted infection; VCT: Voluntary counseling \& testing; ORu: Univariate odds ratios; Cl: Confidence intervals; AOR: Adjusted odds ratios.

\section{Competing interests}

The authors declare that they have no competing interests.

\section{Authors' contributions}

Both authors contributed the design of this research. YC drafted the manuscript and has been involved in the interpretation of the data. $Y C$ and $J L$ performed statistical analyses; $Y C$ and $J L$ played a major role in the field survey. YC and JL made a substantial contribution to the interpretation of the data and had been involved in revision of the manuscript through all stages. Both authors read and approved the final manuscript.

\section{Acknowledgements}

The authors would like to thank all study participants, fieldworkers and volunteers helped in the data collection.

\section{Funding}

This study was funded by (or in part by) the National Natural Science Funds (71273174) and the New Hundred Program on Outstanding Teacher of the School of Medicine of Shanghai Jiao Tong University and the Young Teachers Overseas Visiting and Training Program from Shanghai Municipal Education Commission, Key Discipline Construction of Health Economics from Shanghai Health Bureau. The funders had no role in study design, data collection and analysis, decision to publish, or preparation of the manuscript.

\section{Author details}

${ }^{1}$ School of Public Health affiliated with School of Medicine, Shanghai Jiaotong University, No.227, South Chongqing Road, Shanghai 200025, PR China. ${ }^{2}$ Centre for Health Behaviors Research, School of Public Health and Primary Care, Faculty of Medicine, The Chinese University of Hong Kong, 5/F., School of Public Health, Prince of Wales Hospital, Shatin, NT, Hong Kong 030000, PR China.

Received: 6 November 2013 Accepted: 10 April 2014

Published: 16 April 2014

\section{References}

1. Hao C, Yan H, Yang H, Huan X, Guan W, Xu X, Zhang M, Tang W, Wang N, GU J, Lau JT: The incidence of syphilis, HIV and HCV and associated factors in a cohort of men who have sex with men in Nanjing, China Sex Transm Infect 2011, 87(3):199-201.

2. Zhong F, Lin P, Xu H, Wang Y, Wang M, He Q, Fan L, Li Y, Wen F, Liang Y, Raymond HF, Zhao J: Possible increase in HIV and syphilis prevalence among men who have sex with men in Guangzhou, China: results from a respondent-driven sampling survey. AIDS Behav 2011, 15(5):1058-1066.

3. Xu JJ, Reilly KH, Lu CM, Ma N, Zhang M, Tang W, Wang N, Gu J, Lau JT: A cross-sectional study of HIV and syphilis infections among male students who have sex with men (MSM) in northeast China: implications for implementing HIV screening and intervention programs. BMC Public Health 2011, 11:287.

4. Lau JT, Lin C, Hao C, Wu X, Gu J: Public health challenges of the emerging HIV epidemic among men who have sex with man in China. Public Health 2011, 125(5):260-265.

5. Virtual AIDS Office of Hong Kong: PRiSM - HIV Prevalence and Risk behavioural Survey of Men who have sex with men in Hong Kong 2011. http://www.info.gov. hk/aids/english/surveillance/sur_report/prism2011e.pdf, accessed 6 June 2013.

6. Grier S, Bryant CA: Social marketing in public health. Annu Rev Public Health 2005, 26:319-339.

7. Lau JT, Cai W, Tsui HY, Cheng J, Chen L, Choi KC, Lin C: Prevalence and correlates of unprotected anal intercourse among Hong Kong men who have sex with men traveling to Shenzhen. China AIDS Behav 2013, 17(4):1395-1405. 
8. Sullivan PS, Salazar L, Buchbinder S, Sanchez TH: Estimating the proportion of HIV transmissions from main sex partners among men who have sex with men in five US cities. AIDS 2009, 23(9):1153-1162.

9. Wagner GJ, Aunon FM, Kaplan RL, Rana Y, Khouri D, Tohme J, Mokhbat J: A qualitative exploration of sexual risk and HIV testing behaviors among men who have sex with men in Beirut, Lebanon PLoS One 2012, 7(9):e45566

10. Zhang L, Chow EP, Wilson DP: Distributions and trends in sexual behaviors and HIV incidence among men who have sex with men in China. BMC Public Health 2012, 12:546.

11. Hao C, Lau JT, Zhao X, Yang H, Huan X, Yan H, Gu J: Associations between perceived characteristics of the peer social network involving significant others and risk of HIV transmission among men who have sex with men in China. AIDS Behav 2013, 18(1):99-110. Epub ahead of print.

12. Yang H, Hao C, Huan X, Yan H, Guan W, Xu X, Zhang M, Tang W, Wang N, Lau JT: HIV incidence and associated factors in a cohort of men who have sex with men in Nanjing, China Sex Transm Dis 2010, 37(4):208-213.

13. Matson PA, Chung SE, Sander P, Millstein SG, Ellen JM: The role of feelings of intimacy on perceptions of risk for a sexually transmitted disease andcondom use in the sexual relationships of adolescent African-American females. Sex Transm Infect 2012, 88(8):617-621.

14. Murray CC, Hatfield-Timajchy K, Kraft JM, Bergdall AR, Habel MA, Kottke M, Diclemente RJ: In their own words: romantic relationships and the sexual health of young African American women. Public Health Rep 2013, 128(1):33-42.

15. Jadack RA, Fresia A, Rompalo AM, Zenilman J: Reasons for not using condoms of clients at urban sexually transmitted diseases clinics. Sex Transm Dis 1997, 24(7):402-408.

16. Bernstein E, Ng V, McCloskey L, Vazquez K, Ashong D, Stapleton S, Cromwell J, Bernstein J: Qualitative analysis of cocaine and heroin users' main partner sex-risk behavior: is safety in love safety in health? Addict Sci Clin Pract 2013, 8(1):10.

17. Golub SA, Starks TJ, Payton G, Parsons JT: The critical role of intimacy in the sexual risk behaviors of gay and bisexual men. AIDS Behav 2012, 16(3):626-32.

18. Carballo-Diéguez A, Dolezal C: HIV risk behaviors and obstacles to condom use among Puerto Rican men in New York City who have sex with men. Am J Public Health 1996, 86(11):1619-1622.

19. Lau JT, Cai WD, Tsui HY, Chen JQ: Psychosocial factors in association with condom use during commercial sex among migrant male sex workers living in Shenzhen, mainland China who serve cross-border Hong Kong male clients. AIDS Behav 2009, 13(5):939-948.

20. Muñoz-Laboy M, Castellanos D, Westacott R: Sexual risk behaviour, viral load, and perceptions of HIV transmission among homosexually active Latino men: an exploratory study. AIDS Care 2005, 17(1):33-45.

21. Nyoni JE, Ross MW: Condom use and HIV-related behaviors in urban Tanzanian men who have sex with men: a study of beliefs, HIV knowledge sources, partner interactions and risk behaviors. AIDS Care 2013, 25(2):223-229.

22. Crepaz N, Marks G, Mansergh G, Murphy S, Miller LC, Appleby PR: Age-related risk for HIV infection in men who have sex with men: examination of behavioral, relationship, and serostatus variables. AIDS Educ Prev 2000, 12(5):405-415

23. Young SD, Szekeres G, Coates $T$ : The relationship between online social networking and sexual risk behaviors among Men who have Sex with Men (MSM). PLoS One 2013, 8(5):e62271.

24. Golden MR, Brewer DD, Kurth A, Holmes KK, Handsfield HH: Importance of sex partner HIV status in HIV risk assessment among men who have sex with men. J Acquir Immune Defic Syndr 2004, 36(2):734-742.

25. Arnold MP, Struthers H, Mclntyre J, Lane T: Contextual correlates of per partner unprotected anal intercourse rates among MSM in Soweto, South Africa. AIDS Behav 2013, 17(Suppl 1):S4-S11.

26. Kelly JA, St Lawrence JS, Amirkhanian YA, DiFranceisco WJ, Anderson-Lamb M, Garcia LI, Nguyen MT: Levels and predictors of HIV risk behavior among black men who have sex with men. AIDS Educ Prev 2013, 25(1):49-61.

27. Tieu HV, Xu G, Bonner S, Spikes P, Egan JE, Goodman K, Stewart K, Koblin BA: Sexual partner characteristics, serodiscordant/serostatus unknown unprotected anal intercourse and disclosure among human immunodeficiency virus-infected and uninfected black men who have sex with men in New York City. Sex Transm Dis 2011, 38(6):548-554.
28. Choi KH, Operario D, Gregorich SE, McFarland W, MacKellar D: Substance use, substance choice, and unprotected anal intercourse among young Asian American and Pacific Islander men who have sex with men. AIDS Educ Prev 2005, 17(5):418-429.

29. Zea MC, Reisen CA, Poppen PJ, Bianchi FT: Unprotected anal intercourse among immigrant Latino MSM: the role of characteristics of the person and the sexual encounter. AIDS Behav 2009, 13(4):700-715.

30. Dunne EM, Freedlander J, Coleman K, Katz EC: Impulsivity, expectancies, and evaluations of expected outcomes as predictors of alcohol use and related problems. Am J Drug Alcohol Abuse 2013, 39(3):204-210.

31. Dévieux J, Malow R, Stein JA, Jennings TE, Lucenko BA, Averhart C, Kalichman S: Impulsivity and HIV risk among adjudicated alcohol- and other drug-abusing adolescent offenders. AIDS Educ Prev 2002, 14(5):24-35.

32. Semple SJ, Zians J, Grant I, Patterson TL: Methamphetamine use, impulsivity, and sexual risk behavior among HIV-positive men who have sex with men. J Addict Dis 2006, 25(4):105-114.

33. Magnani R, Sabin K, Saidel T, Heckathorn D: Review of sampling hard-toreach and hidden populations for HIV surveillance. AIDS 2005, 19(Suppl 2):S67-S72.

34. Tang W, Huan X, Mahapatra T, Tang S, Li J, Yan H, Fu G, Yang H, Zhao J, Detels R: Factors associated with unprotected anal intercourse among men who have sex with men: results from a respondent driven sampling survey in Nanjing, China, 2008. AIDS Behav 2013, 17(4):1415-1422.

35. Carballo-Diéguez A, Balan I, Marone R, Pando MA, Dolezal C, Barreda V, Leu CS, Avila MM: Use of Respondent Driven Sampling (RDS) Generates a Very Diverse Sample of Men Who Have Sex with Men (MSM) in Buenos Aires, Argentina PLoS One 2011, 6(11):e27447.

36. Wei C, McFarland W, Colfax GN, Fuqua V, Raymond HF: Reaching black men who have sex with men: a comparison between respondent-driven samplingand time-location sampling. Sex Transm Infect 2012, 88(8):622-626

37. Ramirez-Valles J, Heckathorn DD, Vazquez R, Diaz RM, Campbell RT: From networks to populations: the development and application of respondent-driven sampling among IDUs and Latino gay men. AIDS Behav 2005, 9(4):387-402

38. Heckathorn DD, Semaan S, Broadhead RS, Hughes JJ: Extensions of respondent-driven sampling: a new approach to the study of injection drug users aged 18-25. AIDS Behav 2002, 6:55-67.

39. Heckathorn DD: Respondent-driven sampling II: deriving valid population estimates from chain- referral samples of hidden population. Soc Probl 2002, 49:11-34.

40. Gu J, Wang R, Chen H, Lau JT, Zhang L, Hu X, Lei Z, Li Z, Cai H, Wang T, Tsui $\mathrm{H}$ : Prevalence of needle sharing, commercial sex behaviors and associated factors in Chinese male and female injecting drug user populations. AIDS Care 2009, 21(1):31-41.

41. Lau JT, Gu J, Tsui HY, Wang Z: Prevalence and associated factors of intention to participate in HIV voluntary counseling and testing for the first time among men who have sex with men in Hong Kong, China Prev Med 2013, 57(6):813-818

42. Eysenck SBG, Pearson PR, Easting G, Allsopp JF: Age norms for impulsiveness, venturesomeness and empathy in adults. Personality and individual. Differences 1985, 6(5):613-619.

43. Lijfijt $\mathrm{M}$, Kenemans $\mathrm{J}$, Caci H: Validation of the Dutch translation of the 17 questionnaire. Pers Indiv Differ 2005, 38:1123-1133.

44. Wejnert C: An empirical test of respondent-driven sampling: point estimates, variance, degree measures, and out-of-equilibrium data. Sociol Methodol 2009, 39(1):73-116.

45. Fan S, Sun YM, Lu HY, Ma XY, Yue H, He X, Ma W, Li XF, Xiao Y, Ruan $Y H$, Shao $Y M$ : Analysis on the relationship between condom social norms and unprotected anal intercourse among men who have sex with men in Beijing (in Chinese). Zhonghua Liu Xing Bing Xue Za Zhi 2011, 32(5):473-476.

46. Berry M, Wirtz AL, Janayeva A, Ragoza V, Terlikbayeva A, He X, Ma W, Li XF, Xiao Y, Ruan YH, Shao YM: Risk factors for HIV and unprotected anal intercourse among men who have sex with men (MSM) in Almaty, Kazakhstan PLoS One 2012, 7(8):e43071.

47. Stokols D: Translating social ecological theory into guidelines for community health promotion. Am J Health Promot 1996, 10:282-298 
48. El-Bassel N, Witte SS, Gilbert L, Elwin W, Chang M, Hill J, Steinglass P: The efficacy of a relationship-based HIV/STD prevention program for heterosexual couples. Am J Public Health 2003, 93:963-969.

49. Harvey SM, Kraft JM, West SG, Taylor AB, Pappas-Deluca KA, Beckman LJ: Effects of a health behavior change model-based HIV/STI prevention intervention on condom use among heterosexual couples: a randomized trial. Health Educ Behav 2009, 36(5):878-894.

50. El-Bassel N, Wechsberg WM: Couple-based behavioral HIV interventions: placing HIV risk-reduction responsibility and agency on the female and male dyad. Couple Family Psychol 2012, 1(2):94-105.

51. Mustanski B, Newcomb ME, Clerkin EM: Relationship characteristics and sexual risk-taking in young men who have sex with men. Health Psychol 2011, 30(5):597-605.

52. Difranceisco W1, Ostrow DG, Chmiel JS: Sexual adventurism, high-risk behavior, and human immunodeficiency virus-1 seroconversion among the Chicago MACS-CCS cohort, 1984 to 1992. A case-control study. Sex Transm Dis 1996, 23(6):453-460.

53. Kalichman SC, Johnson JR, Adair V, Rompa D, Multhauf K, Kelly JA: Sexual sensation seeking: Scale development and predicting AIDS-risk behavior among homosexually active men. J Pers Assess 1994, 62:385-397.

54. Kalichman SC, Rompa D: Sexual sensation seeking and sexual compulsivity scales: reliability, validity, and predicting HIV risk behavior J Pers Assess 1995, 65:586-601.

55. Kahn JA, Kaplowitz RA, Goodman E, Emans SJ: The association between impulsiveness and sexual risk behaviors in adolescent and young adult women. J Adolesc Health 2002, 30(4):229-32.

56. Lejuez CW, Bornavalova MA, Daughters SB, Curtin JJ: Differences in impulsivity and sexual risk behavior among inner-city crack/cocaine users and heroin users. Drug Alcohol Depend 2005, 77:169-175.

57. Morgenstern J, Irwin TW, Wainberg ML, Parsons JT, Muench F, Bux DA Jr, Kahler CW, Marcus S, Schulz-Heik J: A randomized controlled trial of goal choice interventions for alcohol use disorders among men who have sex with men. J Consult Clin Psychol 2007, 75(1):72-84.

58. Liddle HA, Dakof GA, Parker K, Diamond GS, Barrett K, Tejeda M: Multidimensional family therapy for adolescent drug abuse: results of a randomized clinical trial. Am J Drug Alcohol Abuse 2001, 27(4):651-688.

doi:10.1186/1471-2334-14-205

Cite this article as: Cai and Lau: Multi-dimensional factors associated with unprotected anal intercourse with regular partners among Chinese men who have sex with men in Hong Kong: a respondent-driven sampling survey. BMC Infectious Diseases 2014 14:205.

\section{Submit your next manuscript to BioMed Central and take full advantage of:}

- Convenient online submission

- Thorough peer review

- No space constraints or color figure charges

- Immediate publication on acceptance

- Inclusion in PubMed, CAS, Scopus and Google Scholar

- Research which is freely available for redistribution 